\title{
Modern graduate student mentors: Evidence-based best practices and special considerations for mentoring undergraduates in ecology and evolution
}

\author{
Emily G. Weigel \\ Emily G. Weigel (weigelem@msu.edu),Department of Zoology, Michigan State University and the BEACON Center \\ for the Study of Evolution in Action, East Lansing, MI 38824
}

\begin{abstract}
This article serves as a short 'best practices' aimed at graduate students for advising undergraduates, specifically within the disciplines of ecology and evolution. It offers documented research on undergraduate research experiences, and the most effective mentoring strategies for success across Science, Technology, Engineering, and Mathematics (STEM) disciplines, as well as practical methods for how to enact these strategies. Most importantly, this work serves particularly to highlight issues undergraduates may encounter in conducting research specifically in ecology and evolution, and what graduate student mentors can do to help students overcome these challenges.
\end{abstract}

Keywords: mentoring, undergraduate research, graduate students, multi-level mentoring.

\section{Introduction}

Authentic science practices, such as participation in research, are critical to preparing future scientists (Laursen et al. 2010) and are among the best suggestions for meeting educational needs outlined in national science standards (National Research Council 2012, NGSS Lead States 2013). Although empirical data collected on undergraduate research has been sparse (Katkin 2003), recent estimates suggest increased promotion and participation in undergraduate research (Laursen et al. 2010), particularly among underrepresented minorities and women (Russell 2005). The
American Council of Learned Societies estimated in 2007 that over $39 \%$ of undergraduates across the United States are participating in research, with as high as $80 \%$ at more STEM-focused institutions (Merkel 2001). This is not unique to the U.S., as across the world, undergraduate research is becoming a staple of undergraduate education.

With growing expectations placed on research advisors, the academic environment increasingly selects for success in balancing research, teaching, and service demands. Thus, not only is undergraduate research on the rise, but also the number of reference guides for faculty intended to increase effective and efficient mentoring in undergraduate research (Laursen et al. 2010). However, given that time-limited faculty often delegate graduate students the task of mentoring undergraduates (Dooley et al. 2004, Gonzalez 2001, Wood 2003), the cultivation of mentoring ability is of particular importance to graduate students, as their current and future success will likely be tied to their ability to effectively and efficiently mentor students.

Although mentoring has been traditionally defined as a relationship to develop the mentee's career (Kram 1985, Levinson 1978, Ragins and Kram 2008), here I provide evidence that there are unique advantages for everyone involved when mentoring takes place between graduate and undergraduate students. Because these advantages may come with challenges, this article offers advice to graduate students on some modern and projected mentoring challenges within ecology and evolution specifically, as well as highlights some best practices in mentoring that may apply regardless of discipline. 


\section{Benefits to Graduate Student Mentors}

Undoubtedly, since the inception of undergraduate research and the first publication studying it (Drinker 1912), researchers may have been mostly interested in the personal benefits of undergraduate mentoring. One very common misconception is that mentoring provides benefits only to the mentee (Sandler 1995). However, as a graduate student mentor, there are a variety of adventages that not only improve your science, but also your ability to support others in the pursuit of knowledge.

First, working with undergraduates helps you to develop mentoring skills, which can be used to demonstrate effective mentorship to future employers and increase diversity in your field of work. The best mentors are more likely to recruit and keep better students (National Academy of Science 1997), which can translate into better research and the potential for a high-performing team-far more productive than a single scientist alone (Dooley et al. 2004, Katzenbach and Smith 1993). Given that many students who participate in undergraduate research pursue advanced degrees (Laursen et al. 2010), your former students may also become future colleagues (Dreher and Dougherty 1997, Lyons et al. 2003). Because mentorship is also critical in increasing opportunities and access for women and minorities (Association of Women in Science 1997, Suedkamp Wells et al. 2005), mentoring undergraduates provides a direct mechanism to benefit, grow, and shape your field.

Second, working with undergraduate students forces you to keep up with literature in your field, and to test some critical assumptions of your work (National Academy of Science 1997). The students beginning research likely do not have the literature background you do. In helping your students to build the theoretical knowledge they need to understand the scope of your work, you and your students will likely encounter research that is more recent and perhaps new to you. Because long-standing theoretical frameworks in the field do not encumber these students, their ideas may call to attention, or even challenge, some critical assumptions. In short, mentees keep you reading and questioning in fresh ways.

Third, working with undergraduate students as a mentor may improve your mentor-mentee relationship with your advisor. Academia is a career with firm deadlines and little time. Thus, through your mentorship of undergraduates in the lab, you save your advisors' time-an often well-appreciated act. When you foster your undergraduates' independence and help to handle issues that arise which do not specifically require your advisor's help, you buffer your advisor from a lot of extra meetings and emails which detract from the amount of time he or she has to mentor all of their students, including you. Because you will likely need your advisor's particular, expert advice, you are helping to also protect your access to your advisor. This allows you as a student to learn how to streamline processes, such as scheduling meetings and receiving feedback, to get the most out of your mentor-mentee relationship. Simply, through mentoring your own students, you will gain an appreciation for mentorship and how to best leverage your unique relationship with your advisor to get things done. This may improve your ability to provide regular updates on progress, resolve problems yourself before seeking help, meet only when necessary, and come prepared to meetings ready to decide on the next steps (Harvard Business Essentials Series 2005).

Fourth, the cooperative skills of managing a team of undergraduates can boost research productivity. A single scientist is not likely to be as productive as a cohesive group working on the same problem (Dooley et al. 2004, Katzenbach and Smith 1993). Although it is critical that a graduate student leading such a team takes steps to ensure quality work is being produced, there are tasks that undergraduates can complete that move research along. These tasks can include helping in collecting data, assimilating references, and drafting work (e.g., a project summary or methods) that may be used in a later publication. This mentee progress can help you sustain effort on projects, although the degree to which you allow your students autonomy in the process of authentic research often varies culturally and between labs. Some evidence suggests that faculty report decreased productivity in working with students (Hunter et al 2009). However, this appears to be mostly experienced by faculty nearing tenure decisions reflecting on single-summer, short-term undergraduate research (Hunter et al 2009). The pressures on faculty are the largest when approaching tenure, and undergraduate students have very little time to learn and carry out research in shorter-term programs. Thus, productivity increases, not decreases, may be more the norm when regularly working with students in cooperative research teams.

Finally, more obvious benefits include a greater sense of satisfaction at work and greater intrinsic benefits linked to increased collegiality and stimulation from working with students (Laursen et al. 2010, National Academy of Science 1997). Research explicitly investigating gains for graduate students has also found increased self-awareness and meta-cognitive abilities (Ploetzner et al. 1999), improved qualifications and career preparation, and improved teaching and communication skills among a list of benefits nearly twice as long as the list of challenges faced by graduate mentors (challenges covered in detail below; Dolan and Johnson 2009). Undoubtedly, there are more benefits than are listed here, and I encourage you to discover more as you engage students in research. 


\section{Benefits to Undergraduate Mentees}

The benefits for undergraduate students may seem a bit more obvious, but they are nonetheless important to promote within research-based disciplines. A growing number of articles address the potential benefits for undergraduates who are involved in research and expand on the students' gains (Bauer and Bennett 2003, Hathaway et al. 2002, Hunter et al. 2007, Kardash 2000, Kremer and Bringle 1990, Lopatto 2004, Rauckhorst et al. 2001, Russell et al. 2007, Seymour et al. 2004). Drawing mainly from evidenced claims reviewed and supplemented in Lopatto (2003a) and Seymour et al. (2004), the benefits for undergraduates include:

- Increased confidence, independence, and perseverance in the face of obstacles

- Improved skills in communication, laboratory methods, critical thinking and problem-solving

- Deepened knowledge of the field

- Increased understanding of the nature of research and working in a scientific field

- General gains of collegial relationships with professors and peers, as well as a glimpse at what life as a graduate student is like

- Achieving better GPAs, attending graduate school, and a career in science, particularly for students from underrepresented groups

As is clear here, undergraduate students benefit both personally and professionally through participation in research, and those effects can have a lasting influence on these students. Given that graduate student mentors are closer in age and in academic hierarchical status, undergraduates may receive additional benefits by being mentored specifically by graduate students (Dolan and Johnson 2009). Thus, the aforementioned benefits may be effectively facilitated by the authentic, empathetic, and engaging perspective most graduate students can offer having been undergraduates recently themselves (Liang et al. 2002).

\section{Concerns to Consider}

Given the wide array of research-supported benefits to students, in addition to your gains as a mentor, engaging undergraduates in authentic research should be a clearly beneficial practice. I would, however, be remiss if I did not mention some of the most common issues mentors have cited while engaging students in undergraduate research.

One of the most frequently cited issues is balancing quality undergraduate research mentoring among other demands (e.g. Desai et al. 2008, Wood 2003). Many mentors view and use undergraduate research as an educational tool, which means occasionally sacrificing research productivity to instruct students (Dolan and Johnson 2009). This can be especially difficult while balancing the greater demands of teaching loads, family priorities, and service that mentors may simultaneously be expected to do.

Likewise, students require an investment of time (e.g., training, meetings) and trust to conduct research. While the amount of required time and trust may change as students gain experience in research (Branchaw et al. 2010, Dolan and Johnson 2009), the initial investments may appear to outweigh future benefits at quick glance. Difficulties in mentoring may also arise through unclear or incompatible expectations (Young and Perrewe 2000), lack of mentor experience (Eby et al. 2004), and the level to which mentors treat mentees as equals versus protégés (French and Russell 2002, Haith-Cooper 2003, Solomon and Crowe 2001).

There are always some costs associated with undergraduate mentoring (e.g., checking student progress, ensuring their safety, and inspecting the quality of their research: Dolan and Johnson 2009; time spent on creating feasible, educational ways to involve undergraduates in research: Branchaw et al. 2010). However, the costs do not outweigh the benefits to these students or the field, particularly if we wish to advance research in the next generation of scientists. We must, however, be careful to craft our mentorship appropriately, effectively, and intentionally, as negative experiences in mentoring have been shown to have greater explanatory power than positive experiences in predicting protégé outcomes (Eby and Allen 2002, Eby et al. 2004). We then ask, if well-prepared mentors who are motivated to work with students are an excellent starting point for mentoring relationships (Dolan and Johnson 2009), what else can graduate mentors do to facilitate undergraduate mentee success?

\section{Best Practices in STEM Mentoring}

Generally, great research mentoring relationships are built on the ability to share wisdom and technical expertise, while remaining enthusiastic about, available to, and trusting of the mentee. Good mentors make an effort to see the world from their mentee's vantage point, professionally and personally, while guiding students to greater scientific understanding. Although directed broadly toward mentoring both graduate and undergraduate students, "Nature's guide for mentors" (Lee et al. 2007), provides self-assessment questions useful in reflecting on your own mentoring and understanding to what degree you respect the varied goals and interests of your mentees. Similarly, a more rigorous assessment, Mentoring Competency Assessment, has been developed specifically to be used as a tool for mentors and mentees to assess mentoring skills of research mentors (Fleming et al. 2013). Below is a 
sampling of some of best practices in STEM mentoring, largely based on the work developed in Handelsman et al. (2005) and updates since, particularly Sorkness et al. (2013) and Pfund et al. (2013). Mentoring is dependent on those involved in the mentoring relationship, and each mentoring relationship is necessarily unique. Thus, it is especially important for graduate students to explore these tactics and use those that work best for them and their mentees.

One of the most important first steps of any relationship can be to set ground rules. Consider establishing expectations and clearly communicating them to the mentee via a "Mentoring Compact" or "Contract" (Handelsman et al. 2005, Lyons et al. 2003). This should clearly establish the goals for the mentoring relationship, and is ideally constructed with input of both the mentee and mentor. It should be tailored to the mentee's knowledge and skill level and adjusted to account for differences in the working style and meeting frequency of mentors and mentees. It should also have provisions for mid-term assessment and handling conflict, should it arise. Use this document to set a tone that encourages feedback both on the research at hand as well as the mentoring relationship.

Communication should not stop after expectations are established; rather, communicate with your mentee regularly (Brown et al. 1999), and keep in mind that the ways and technologies that they use to communicate may be different than yours. Try to foster open communication by discussing what technologies they use most to communicate, and attempting to use those when appropriate and approved by your institution. Mentors may also have preferences for how to receive certain types of information, thus mentors should clearly indicate how professional contact should proceed if using media other than email (e.g., clarify when a text message or tweet is inappropriate). More importantly, set boundaries on the hours and places where you can be contacted. Protect your time while keeping available.

While it can be important to keep a professional distance, do share your backstory, including your educational history and what sparked your interest in science. Include in this narrative what has happened to reach this point in your career, including any professional organizations, experiences, or courses which were pivotal in your scientific development (Handelsman et al. 2005). As a graduate mentor, you may also want to share stories of rejections and difficulties to help students understand that some setbacks are normal and can be overcome. Consider sharing a draft of a manuscript that has been edited by your advisor. This will give undergraduate students the idea that constructive criticism is about improving good ideas, not shutting others down, while emphasizing grit and perseverance as traits to build (Duckworth et al. 2007).
Additionally, gauge your students' prior and growing knowledge within the field, and consider diverse strategies to fill in knowledge gaps and correct errors as they arise. This will severely impact how students conduct a research project, from its inception to final presentation. Remember, mentors should foster their mentees' independence in scientific research by displaying trust and understanding (National Academy of Science 1997). Understand that you play a pivotal, and often dominant, role in your students' development, but stimulate their creative and independent thought by seriously considering student ideas and, when appropriate, letting them work on their own.

As best as possible, design student projects that allow mentees to quickly get started and accomplish set objectives within a given timeframe (Handelsman et al. 2005). Ideally, projects should be based on hypotheses with relatively clear expected results. Be sure your mentees grasp that research does involve some risk and uncertainty, and that success is not necessarily guaranteed. Help your mentees transition from frequent grades given in courses to less-often, but much more detailed, constructive feedback from research mentors. Verify student receipt and understanding of feedback by asking them to summarize comments from a meeting and send it to you, or by using email tracking software (e.g., YesWare or DidTheyReadIt) and progress logs when working remotely. These tactics should be carried out with the mentee's consent and allow you to assess if, when, and how mentees are getting messages and using them to make progress. This also allows for the development of a long-term log to which you and the students can refer should issues in communication arise.

$\mathrm{Be}$ an advocate that mentees become more than just 'grunt labor' within the labs of your institution. Students are often expected by employers and many graduate advisors to be involved in multiple labs using various techniques during their research career. While it is useful that they learn the techniques of your lab, some of the skills they should learn will be transferrable to their schoolwork and other professions. For this reason, encourage students to learn a variety of skills, such as how to conduct literature searches, write research papers, and use reference managing software (e.g. EndNote or Zotero). Exposing students to campus or online resources to conduct literature searches (e.g., via ISI Web of Knowledge or Pubmed) is an invaluable skill that may be overlooked in their regular curriculum, and even if addressed, can be supplemented by the search parameters used in your field. Learning how to conduct literature searches and document correctly allows students to contribute more intellectually to research, and importantly, will also shave off valuable time from their paper writing within courses. Becoming comfortable with primary literature takes time, but learning software to manage references will also ease 
the transition from textbooks and allows mentees to begin to assess validity and assumptions of claims, expand their vocabulary and viewpoints on big questions, and to be exposed to other methods. Consider, too, having students present in lab group meetings or at conferences. This will not only teach them effective presentation skills, but also how to respond to tough questions and realize the limits of their own and current scientific knowledge.

Likewise, promote your student's development by getting them to engage within the larger research community (National Academy of Science 1997, Wenger et al. 2002). Here, graduate mentors and faculty members may want to discuss holding research group meetings where undergraduate attendance is expected. Have students read and share their work as a lesson in how peer-review functions within science, and consider involving students in outreach activities to see how science is translated to the public.

Many students are also unaware that professional societies exist for their discipline. Exposure to professional society activities, including opportunities to network, present findings, and find funding for research, is critical to help students transition into scientific careers. One way to do this is by promoting professional society emailing lists (listservs; e.g., Ecolog and EvolDir) which can be useful to show mentees the diverse array of research being conducted worldwide, where they may find funded graduate positions (should they continue research), and how to ask for assistance in a professional manner. Opportunities exist as well for undergraduates to submit articles, request funding, and present at conferences. As a graduate student, you can facilitate mentee professional development by finding transport or funding for students to attend conferences, taking them to important talks, and providing introductions to build your mentee's professional network.

Enhance your mentee's career by promoting their strengths, nominating or encouraging your advisor to nominate them for awards (Dreher and Dougherty 1997), and helping them develop multiple mentors (Suedkamp Wells et al. 2005). Keep in mind that promoting your mentees can build rapport, so attend their presentations, invite others, and email or tweet about their awards, abstracts, or copies of their finished work. Try to take pictures and if they are comfortable, film, so that they may use these items on a professional website. Promote their work and let them know you are proud of the work that they do.

Because it will certainly affect the personal and professional development of your mentees, keep diversity in mind as you mentor (Handelsman et al. 2005). Relationships are impacted by the biases and prejudices we all hold, so make sure you increase your own cultural competency and discuss issues in diversity when they arise. Role model the behavior you expect from students, and understand that many axes of diversity (background, position of power, first language, etc.) can alter the intent and the perception of what is said and heard. Be open to having group discussions about diversity as a matter of the greater schema of ethics training you give your students. Consider assignments to visit the Project Implicit website, where students can examine their own subconscious thoughts on various aspects of diversity: https://implicit.harvard. edu/implicit/.

Another way you as a mentor can understand diversity is by involving other mentors in your mentorship development. One potential avenue is to participate in mentor communities designed to improve your mentoring. You can engage in mentor communities in informal (e.g., conversations in social settings, wikis, online forums) and formal (e.g., workshops) ways to construct and receive feedback on mentoring philosophies. Take advantage of online or other resources offered through the Center for the Integration of Research, Teaching and Learning (CIRTL, www.cirtl.net). Consider collaborations with other mentors to train and conduct mentee professional development, and be sure to utilize the expertise of faculty and student resources on campus, such as an undergraduate research offices and academic advisors. Practical guides, such as the Entering Mentoring manual (Handelsman et al. 2005), can be useful to walk mentors through developing goals and expectations for mentoring in academic relationships, and several mentoring programs exist through outside organizations, including the Association of Women in Science (AWIS; http://www.awis.org/?Mentoring) and MentorNet. (http: //www.mentornet.net/).

More important than any other suggestion, be aware of yourself and what your specific strengths and weaknesses are as a mentor (Handelsman et al. 2005). See the opportunity to mentor an undergraduate as an investment in your development as a researcher, and as such, model professional behavior. Authenticity, metacognition, and assessment of the mentor-mentee relationship is not only for the benefit of your student, but for you as their mentor. No matter your philosophy on mentoring, you will need help on occasion, and it is well worth the time to know also what your advisor expects of you as a research mentor. Know what matters (and what does not) in mentoring and how that may be transferred to your relationship with your own advisor. Appreciate the similarities and differences in these relationships, acknowledge difficulties, and celebrate the successes.

\section{Special Concerns within Ecology and Evolution}

Within every research field, there are cultural elements and expectations that may not be obvious to 
outsiders or even students until significant time spent within the field. Therefore, it is worth the effort to explore the culture of your own discipline with respect to many aspects of academic life. Below I offer some particular observations of ecology and evolution research as they relate, and some strategies to proactively address potential issues.

Undergraduate students that are new to research in ecology and evolution may expect to quickly publish papers that they can use to improve their resume or applications for an advanced degree. It is worth explaining to students, particularly those hopeful to use publications on applications to medical school, that studies within ecology and evolution tend to take relatively longer to complete and publish compared to other fields of biology. Additionally, authorship appears to be more restricted in ecology and evolution, and therefore papers may include a smaller list of authors than other subfields of biology, particularly within the United States. We need explicit research to solidify these observed patterns, but until theses data have been mined, students who arrive with expectations of authorship on several papers deserve to be informed about this perceived difference and what it might mean to their aspirations. Students still wishing to engage in projects can find other modes of communicating science, including presenting at conferences and publishing smaller projects in one of the growing number of journals for undergraduate research (e.g. BIOS, EvoS, The Tower). This can be a mechanism by which students can show research productivity in the delay to publication in a traditional journal.

Stress to students that it is the questions, not the species necessarily, that are most important. Interesting things can be done with some of the organisms that, on the surface, appear to be the least captivating. Students who are simply attracted to the species would do well to be given papers to read that do not directly use your study species, yet attempt to answer some of the same questions. Have students concentrate on the benefits and limitations of using your species to answer certain types of questions (e.g., long-term evolution in E. coli would run much faster than in elephants because of generation times). If your students are academically prepared to engage with primary and secondary research, introduce them to review and theory papers that address key assumptions, but are not necessarily restricted to a single species. This will aid them as they plan projects and speak about their work, and give them a broader perspective as they begin to consider graduate work.

Teach your students good communication skills via email, as collaboration, travel, and conducting field research over long distances are common in these fields. Have students send regular emails that detail progress and think about alternative approaches about how to proceed next depending on initial progress. If there is a time-sensitive decision to be made in the field where there may be limited internet access, then the anticipation of future decisions will reduce the number of required emails. As an alternative, consider having students fill out online surveys with their weekly progress. This would allow you to download the survey results and read the progress for several students in a consistent format. If internet is limited, you can view all of your students' progress in a single downloaded item (the response spreadsheet), and prepare text responses offline. The standardized format, thus, allows you to quickly respond to several students at once in your next moment of internet access, minimizing the amount of time you and your mentees spend awaiting feedback.

$\mathrm{Be}$ sure to also account for and inform students of the struggles of field research, if you conduct it. If possible, have students visit the area prior to beginning research, and prepare a handout or webpage which covers the basics of what research at your field site entails. Students new to field work may have questions they are too embarrassed to ask or issues they may not want to disclose. Such information should include what to wear (especially footwear), access to certain resources (particularly restrooms and privacy), what to do about personal medications (particularly for longer stays), how long and what work the students will be doing, and some information on the location. When working in areas that might be politically or culturally challenging, inform your students of any possible risks and issues that have been encountered in the past. Pointing out a history of work in that area and issues faced may ease their concerns by showing them that scientists have encountered, but overcome, these challenges before. Consider having a follow-up meeting where larger groups can have questions efficiently answered at one time, and invite students to email or meet you, should they have lingering or personal questions.

Consider, too, that research is collaborative, but does have isolating moments. Spend time vetting students who can work well both alone and in groups, and in the tedium that sometimes accompanies research. Should students experience mental health issues (e.g. loneliness or isolation), make sure to normalize the use of on- or off-campus resources (e.g., counseling centers), and shield yourself from becoming a counselor. You may be a mentor and a friend, but referring the student to someone trained to provide help is both a personal and professional best practice.

When conducting field research, students may not be used to the isolation one may experience without phone or internet access, so be sure to prepare them for being alone or enjoying the consistent company of a smaller group. Particularly in small research groups or in the field, if issues between individuals arise, deal with them quickly so as not to affect morale. This is good practice to protect your ability at your home university to bring 
students to your selected field site, and the ability to use the field site itself. Lastly, given recent attention paid to the safety of women while conducting research (Clancy et al. 2014), it is important to convey consistent and clear conduct expectations, and stay firm to the idea that those violating this code of conduct will face consequences.

Whether the research occurs in the lab or in the field, keeping lab notebooks and recording data are critically important skills to impart on our mentees. Explore ways to keep records that allow you to monitor and give feedback on methodology and data collection. Given the increase of technology, consider online lab notebooks like iPython or repositories like GitHub, which are wellsuited for long-distance collaboration and coding/ modeling projects. Encourage your students to take pictures as a part of their lab notebooks, record you when you talk, or even create videos suitable for posting to Youtube to demonstrate methods for future lab members or the public. Use technology to your advantage to be sure mentees are following the necessary steps and recording data properly. Be sure, however, that they can convert this diverse media into written word when needed.

Finally, talk to your students about how scientists and scientific work are often perceived. Create or participate in opportunities to do outreach with your students, and model the language and tone you would advise students to use with non-scientific members of the public, and point out how that might differ from speaking with scientists. Be an advocate for science education, but also share the realities of the public perception of science, and how cultural and religious identity may play a role. This may be particularly important for evolution education, as there are unique issues (e.g. Miller et al. 2006, Pew Survey 2013) that may arise in public acceptance and funding for work in this area. These circumstances shape the care with which your mentees address different adversarial groups to promote scientific understandings of the world. Additionally, stress to students that despite the challenges of reaching diverse and, sometimes, oppositional public, the promotion of science is critical to shaping the future of scientific funding, conservation, and public policy, particularly for issues like climate change (Pew Survey 2014) that affect us all.

\section{Conclusions}

Undergraduate research participation is on the rise, actively changing the demography and skill sets demanded of researchers within ecology and evolution, as well as in other scientific fields. Balancing one's research, teaching, and service demands can be aided by the implementation of quality methods in mentoring even as a graduate student. Attention paid to creating the next generation of scientists pays dividends to both you as the mentor and the field as a whole. Overcoming challenges through quality mentoring will help us prepare mentees to meet future scientific challenges, while fostering pleasant work environments in fields which impact the natural world.

\section{Acknowledgements}

The author would like to thank CIRTL mentors Melissa McDaniels, Rique Campa, and Christine Pfund for comments on earlier drafts of this work, and the reviewers for the care and perspective they gave in improving this manuscript. This material is based in part upon work supported by the National Science Foundation under Cooperative Agreement No. DBI0939454. Any opinions, findings, and conclusions or recommendations expressed in this material are those of the author(s) and do not necessarily reflect the views of the National Science Foundation.

\section{Referees}

Brent Stoffer - stoffebm@ mail.uc.edu University of Cincinnati

Hanno Zielke - zielke@ hsp2bio.rwth-aachen.de RWTH Aachen University

\section{References}

Association of Women in Science. 1997. Creating tomorrow's scientists. Models of Community Mentoring. Report on the AWIS Mentoring Project. Association of Women in Science, Washington, D.C., USA.

Bauer, K.W. and J.S. Bennett. 2003. Alumni perceptions used to assess undergraduate research experience. Journal of Higher Education 74:210230. CrossRef

Branchaw, J., Pfund, C., and R. Rediske. 2010. Entering research: A facilitator's manual: workshops for students beginning research in science. W. H. Freeman, New York, NY.

Brown II, M.C., Davis, G.L., and S.A. McClendon. 1999. Mentoring graduate students of color: myths, models, and modes. Peabody Journal of Education 74:105-118. CrossRef

Clancy, K.B.H., Nelson R.G., Rutherford J.N., and K. Hinde. 2014. Survey of Academic Field Experiences (SAFE): Trainees Report Harassment and Assault PLoS ONE 9: e102172.

"Climate Change: Key Data Points from Pew Research." Pew Research Center, Washington, D.C. 
(January 27 2014). http://www.pewresearch.org/keydata-points/climate-change-key-data-points-frompew-research/, accessed August 6 ${ }^{\text {th }}, 2014$.

Desai K.V., Gatson S.N., Stiles T.W., Stewart R.H., Laine GA, and C.M. Quick. 2008. Integrating research and education at research-extensive universities with research-intensive communities. Advances in Physiology Education 32:136-141. CrossRef

Dolan, E. and D. Johnson. 2009. Toward a holistic view of undergraduate research experiences: an exploratory study of impact on graduate/postdoctoral mentors. Journal of Science Education and Technology 18:487-500. CrossRef

Dooley, D.A., Mahon R.M., and E.A. Oshiro. 2004. An undergraduate research opportunity: collaboration between undergraduate and graduate students. Journal of Food Science Education 3:8-13. CrossRef

Dreher, G.F., and T.W. Dougherty. 1997. Substitutes for career mentoring: promoting equal opportunity through career management and assessment systems. Journal of Vocational Behavior 51:110-124. CrossRef

Drinker, C.K. 1912. Undergraduate research work in medical schools. Science 36:729-738. CrossRef

Duckworth, A.L., Peterson, C., Matthews, M.D., and D. R. Kelly. 2007. Grit: Perseverance and passion for long-term goals. Journal of Personality and Social Psychology 92:1087-1101. CrossRef

Eby, L.T. and T.D. Allen. 2002. Further investigation of proteges' negative mentoring experiences: patterns and outcomes. Group and Organizational Management 27:456-479. CrossRef

Eby, L., Butts, M., Lockwood, A., and S.A. Simon. 2004. Proteges' negative mentoring experiences: construct development and nomological validation. Personnel Psychology 57:411-447. CrossRef

Fleming, M., House, S., Hanson, V.S., Yu, L., Garbutt, J., McGee, R., et al. 2013. The Mentoring Competency Assessment: Validation of a new instrument to evaluate skills of research mentors. Academic Medicine 88:1002-1008. CrossRef

French, D. and C. Russell. 2002. Do graduate teaching assistance benefit from teaching inquiry-based laboratories. Bioscience 52:1036-1041. CrossRef

Gonzalez, C. 2001. Undergraduate research, graduate mentoring, and the university's mission. Science 293:1624-1626. CrossRef

Haith-Cooper, M. 2003. An exploration of tutors' experiences of facilitating problem based learning. Part 2- implications for the facilitation of problem based learning. Nurse Education Today 23:65-75. CrossRef

Handelsman, J., Pfund, C., Miller Lauffer, S., and C.M. Pribbenow. 2005. Entering Mentoring: A Seminar to Train a New Generation of Scientists. University of Wisconsin Press, Madison, Wisconsin.

Harvard Business School Press. 2005. Time Management: Increase Your Personal Productivity and Effectiveness (Harvard Business Essentials Series). Boston, Massachusetts.

Hathaway, R.S., Nagda, B.A., and S.R. Gregerman. 2002. The relationship of undergraduate research participation to graduate and professional education pursuit: an empirical study. Journal of College Student Development 43:614-631.

Hunter, A-B., Laursen S.L., and E. Seymour. 2007. Becoming a scientist: the role of undergraduate research in students' cognitive, personal, and professional development. Science Education 91:36-74. CrossRef

Hunter, A,-B., Thiry, H., and Crane, R. 2009. Student outcomes from the LA-STEM Research Scholars Summer Bridge program. An evaluation of the LASTEM Research Scholars program at the Louisiana State University, 2007-2008: Qualitative Results. Ethnography \& Evaluation Research. Center to Advance Research and Teaching in the Social Sciences, University of Colorado, Boulder, Colorado.

Kardash, C.M. 2000. Evaluation of an undergraduate research experience: perceptions of undergraduate interns and their faculty mentors. Journal of Educational Psychology 92:191-201. CrossRef

Katkin, W. 2003. The Boyer Commission Report and its Impact on Undergraduate Research. New Directions for Teaching and Learning 2003:19-38. CrossRef

Katzenbach, J.R. and D.K. Smith. 1993. The Wisdom of Teams: Creating the High-performance Organization. Harvard Business School, Boston, Massachusetts.

Kram, K. 1985. Mentoring at work. Scott and Foresman, Boston, Massachusetts.

Kremer, J.F. and R.G. Bringle. 1990. The effects of an intensive research experience on the careers of talented undergraduates. Journal of Research and Development in Education 24:1-5.

Laursen, S., Hunter, A, Seymour, E., Thiry, H, and G. Melton. 2010. Undergraduate research in the sciences: Engaging students in real science. JosseyBass, San Francisco, California.

Lee, A., Dennis, C. and P. Campbell. 2007. Nature's Guide for Mentors. Nature 447:791-797. CrossRef

Levinson, D. J., 1978. Seasons of a Man's Life. Random House, New York.

Liang, B., Tracy, A.J., Taylor, C.A., and L.M. Williams. 2002. Mentoring college-age women: a relational approach. American Journal of Community Psychology 30:271-288. CrossRef 
Lopatto, D. 2003a. The essential features of undergraduate research. Council on Undergraduate Research Quarterly 24:139-142.

Lopatto, D. 2004. Survey of undergraduate research experiences (SURE): first findings. Cell Biology Education 3:270-277. CrossRef

Lyons, R.E., McIntosh, M., and M.L. Kysilka. 2003. Teaching college in an age of accountability. Pearson, Allyn, and Bacon, Upper Saddle River, New Jersey.

Merkel, C.A. 2001. Undergraduate research at six research universities: A pilot study for the Association of American Universities. California Institute of Technology, Pasadena, California.

National Academy of Science. 1997. Advisor, teacher, role model, friend. On being a mentor to students in science and engineering. National Academies of Science Press, Washington, D.C., USA.

National Research Council.2012. A Framework for K12 Science Education. National Academies of Science Press, Washington, D.C., USA.

NGSS Lead States. 2013. Next Generation Science Standards: For states, by states. National Academies of Science Press, Washington, D.C., USA.

Pfund, C., House, S., Asquith, P., Carney, P., Masters, K.S., McGee, R., et al. 2013. A research mentor training curriculum for clinical and translational researchers. Clinical and Translational Science 6: 26-33. CrossRef

Ploetzner, R., Dillenbourg, P., Praier, M., and D. Traum. 1999. Learning by explaining to oneself and to others. Pages 103-121 in Dillenbourg, P. (ed) Collaborative learning: cognitive and computational approaches. Elsevier, Oxford, United Kingdom.

"Public's Views on Human Evolution." Pew Research Center, Washington, D.C. (DECEMBER 30, 2013) http://www.pewforum.org/2013/12/30/ publics-views-on-human-evolution/, accessed August $6^{\text {th }}, 2014$.

Ragins, B.R. and K.E. Kram. 2008. The handbook of mentoring at work: Theory, research, and practice. Sage, Thousand Oaks, California.

Rauckhorst, W.H., Czaja, J.A., and M. Baxter Magolda. 2001. Measuring the impact of the undergraduate research experience on student intellectual development. Paper presented at Project Kaleidoscope Summer Institute, Snowbird, July 18-21.

Russell, S.H. 2005. Evaluation of NSF support for undergraduate research opportunities: 2003 program participant survey. SRI Project No. P11554. Draft Final Report.

Russell, S.H., Hancock M.P., and J. McCullough. 2007. The pipeline: benefits of undergraduate research experiences. Science 316:548-549. CrossRef

Sandler, B. R. 1995. Mentoring: myths and realities, dangers and responsibilities. Pages 271-279 in Fort,
D.C. (ed.). A handup. Women mentoring women in science. Association of Women in Science, Washington, D.C., USA.

Seymour, E.L., Hunter, A-B., Laursen, S., and T. DeAntoni. 2004. Establishing the benefits of research experiences for undergraduates: first findings from a three-year study. Science Education 88: 493-594. CrossRef

Solomon, P. and J. Crowe. 2001. Perceptions of student peer tutors in a problem-based learning programme. Medical Teacher 23:181-186. CrossRef

Sorkness, C., Pfund, C., Asquith, P., and Drezner, M. 2013. Research Mentor Training: Initiatives of the University of Wisconsin Institute for Clinical and Translational Research. Clinical and Translational Science 6: 256-258. CrossRef

"Student learning and faculty research: Connecting teaching and scholarship (White paper)" Teagle Foundation, American Council of Learned Societies (MAY 2007). http://www.teaglefoundation.org/ learning/publications, accessed November 18, 2014

Suedkamp Wells, K.M., Ryan, M.R., Campa III, H. and K. A. Smith. 2005. Mentoring guidelines for wildlife professionals. Wildlife Society Bulletin 33:565-573. CrossRef

Wenger, E., McDermott, R., and W.M. Snyder. 2002. Cultivating the communities of practice. Harvard Business School, Boston, Massachusetts.

Wood, W.B. 2003. Inquiry-based undergraduate teaching in the life sciences at large research universities: a perspective on the Boyer Commission Report. Cell Biology Education 2:112-116. CrossRef

Young, A.M. and P.L. Perrewe. 2000. What did you expect? An examination of career-related support and social support among mentors and proteges. Journal of Management 26:611-632.

\section{Response to referee}

I am in agreement with and very much appreciate the comments by Stoffer (2015) regarding the potential difficulties that may arise in the process of mentoring. Stoffer does the field and this paper in particular a service by pointing out these concerns and the role that individuals at various levels can play in fostering quality undergraduate research experiences. In this response, I aim to expand and clarify a few of the concerns raised within the context of the literature, as well as propose strategies which can expand the impact of Stoffer's recommendations.

University and research institute aims and size absolutely direct their functioning, including the value placed on undergraduate research. Likewise, the career aspirations of mentors, particularly graduate students, likely factor into the quality and quantity of undergraduate research mentoring that occurs. Research 
has documented that graduate students often feel that research is prioritized over other responsibilities (Anderson et al. 2011, Bianchini et al. 2002); this is reasonable given that current graduation requirements are largely based on producing original research, and other activities (service or teaching) are often seen only as add-ons or means by which the degree is funded. Given that this can be seen as a historical consequence of the structure of many advanced degrees, faculty priorities and mentoring of graduate students typically prioritize research (Austin et al. 2009). Thus, advisors are not likely to see the need to establish a formal mechanism to instruct graduate students on mentoring without data supporting claimed benefits. The importance of research on undergraduate research mentoring is perhaps in solidifying the claims that it indeed produces benefits, particularly to research, as research productivity is one of the main currencies by which many academics are judged.

One of the notable outcomes from the study of undergraduate mentoring is specific, data-supported courses, such as those mentioned in the article and in Stoffer (2015). These research-based courses are supported by the texts mentioned, and can be relatively easily adopted by schools without access to multiinstitutional training (such as that offered by Center for the Integration of Research, Teaching and Learning) to establish their own independent, research-supported mentoring courses. The texts are commercially available, complete with ready-to-use modules, and can be directly used in courses without much modification, although I suggest adding information on universityspecific resources to on-campus training. I am in complete agreement with the reviewer that formalized training needs to increase, if not in a course, at least in workshop form, to best support graduates and the undergraduates they mentor.

A cultural shift to value undergraduate research mentoring is occurring, but not yet fully realized. The availability of funding does indeed impact this relationship (Eagan Jr. 2011), as Stoffer (2015) noted, and assuredly current funding climates are not helping. I agree that finding ways to financially support undergraduate research is critical, however many of the benefits of research and mentoring can be realized by departments with limited funds. Universities can support undergraduate research in low-cost ways by pooling or using existing resources innovatively. For example, maintaining a 'Research Assistant and Volunteer Opportunities' board or website, or a 'Finding a Lab' fair, consolidates efforts to aid graduate students in easily and quickly identifying mentees. Time saved by graduate students can thereby be reallocated to properly introducing mentees to research. Likewise, offering graduate credit for undergraduate research mentoring (as well as undergraduate credit for research), and credit for courses on mentoring, can help graduate students consider their role in the quality of undergraduate research experiences. Additionally, a more active role by the major societies to help fund or contribute to the mentoring of undergraduates, such as workshops at annual meetings or web pages maintained on society websites, can be lower-cost options indicating support and positively affecting the field without breaking the bank. A lack of funding should not be used as a mechanism to excuse poor undergraduate research involvement and experiences.

As Stoffer (2015) addresses, undergraduate research mentoring by graduate students is not conducted in a vacuum, but is indeed a multi-level process. With several individuals involved in mentoring a student, there are benefits, but also clear drawbacks, arguably the largest being how to maintain clear, and nonconflicting, communication (Dolan and Johnson 2009, Dolan and Johnson 2010, Young and Perrewe 2000). In this work, I advocate keeping written logs of undergraduate mentee-graduate mentor communication, but did not make clear that another advantage to this method is the ease by which this information can be quickly shared verbatim. This can help a graduate student keep a professor abreast of what has been discussed with an undergraduate, as well as provide the advisor a method by which to quickly determine student progress and mentoring of the undergraduate by the graduate student. This allows for flexibility while helping to prevent delays in research progress. Additionally, depending on the research group's size, combined meetings with the students (graduate and undergraduate) and updates during lab meetings enhance communication effectiveness and efficiency. However, research into multi-level mentoring has yielded a progressive mentoring model, which proposes that, although graduates, undergraduates, and professors are responsible for maintaining contact, the responsibility is on professors to set the expectations and goals of the group (Santora et al. 2013), and expectations should include communication norms. Maintaining communication across levels is no easy task, but it must be done.

As noted, the length of stay in a laboratory does impact the relative benefits experienced (Adedokun 2013). Given that even relatively long-term undergraduate research experiences in many labs will not produce independent publications, as stated by the reviewer, we must begin to see benefits beyond publications. Even short-term students can be productive and make substantial contributions, and being realistic about expectations can help us and our students recognize their accomplishments. Senior graduate students leaving labs can also help to establish undergraduate researchers before they go, giving more junior research colleagues the ability to observe and benefit from a mentoring relationship within their lab as they begin to navigate 
mentorship responsibilities. Moreover, as noted in this paper, these experiences can help prepare students for future careers, which, for some students, may now include or exclude research in your field as a result of their undergraduate research experiences (Hunter et al. 2007, Lopatto 2004, Seymour et al. 2004). Research by Ragins and Scandura (1999) and Reddick et al. (2012) suggest that those mentored in the past are more likely to express interest in mentoring in the future. Thus, mentorship, even when short-term, can still yield worthwhile benefits personally and professionally.

We have established that there are many players which stand to benefit from undergraduate mentoring, and these individuals can be supported both financially and educationally by departmental and university efforts. In order to continue facilitating an environment which values undergraduate research and mentoring, we must collect data on the status and progress of efforts supporting undergraduate research. As Stoffer (2015) notes, individuals, departments, and universities can collect data to evaluate undergraduate research and mentoring challenges faced in different fields of research within their organization. Approaches to identify unique concerns are on the horizon as we investigate more programs at a wider array of institutions (Thiry et al. 2012). A formalized approach, which invites collaboration with academics from education fields, will allow us to methodically evaluate our strengths and weaknesses with regard to undergraduate research and mentoring specifically within ecology and evolution, and more rapidly formulate and implement plans to address issues. Perhaps another approach is to consider conducting these collaborative analyses at the level of professional societies. This would aid the collection of comparable data to detect field-wide problems. This approach offers the advantage of allowing universities to compare their data against comparably-positioned universities and provide guidance in places where their institution falls short. The data may also bolster negotiations with departments for access to greater support, or become a data-supported 'selling point' for recruiting undergraduates interested in ecology and evolution.

I am appreciative of the reviewer's comments and discussion, and hope this article, and the response comments offered in Stoffer (2015) thereafter, continue discussions to advance mentoring within ecology and evolution.

Adedokun, O.A., Parker, L. C., Childress, A., Burgess, W., Adams, R., Agnew, C. R., Leary, J., Knapp, D., Shields, C., Lelievre, S., and D. Teegarden. 2014. Effect of time on perceived gains from an undergraduate research program. CBE-Life Sciences Education 13:139-148. CrossRef
Anderson, W.A., Banerjee, U., Drennan, C.L., Elgin, S.C.R, Epstein, I.R., Handelsman, J., et al. 2011. Changing the culture of science education at research universities. Science 331: 152-153. CrossRef

Austin, A.E., Campa, H., Pfund, C., Gillian-Daniel, D. L., Mathieu, R., and J. Stoddart. 2009. Preparing STEM doctoral students for future faculty careers. New Directions for Teaching and Learning 2009: 83-95. CrossRef

Bianchini, J.A., Whitney, D.J., Breton, T.D., and B. A. Hilton-Brown. 2002. Toward inclusive science education: University scientists' views of students, instructional practices, and the nature of science. Science Education 86: 42-78. CrossRef

Dolan, E. and D. Johnson. 2009. Toward a holistic view of undergraduate research experiences: an exploratory study of impact on graduate/postdoctoral mentors. Journal of Science Education and Technology 18:487-500. CrossRef

Dolan, E. and D. Johnson. 2010. The UndergraduatePostgraduate-Faculty triad: unique functions and tensions associated with undergraduate research experiences at research universities. CBE-Life Sciences Education 9:543-553. CrossRef

Eagan Jr, M.K., Sharkness, J., Hurtado, S., Mosqueda, C.M., and M.J. Chang. 2011. Engaging undergraduates in science research: not just about faculty willingness. Research in High Education 52: 151-177. CrossRef

Hunter, A-B., Laursen S.L., and E. Seymour. 2007. Becoming a scientist: the role of undergraduate research in students' cognitive, personal, and professional development. Science Education 91:3674. CrossRef

Lopatto, D. 2004. Survey of undergraduate research experiences (SURE): first findings. Cell Biology Education 3:270-277. CrossRef

Ragins, B.R. and T.A. Scandura. 1999. Burden or blessing? Expected costs and benefits of being a mentor. Journal of Organizational Behavior. 20:493509. CrossRef

Reddick, R.J., Griffin, K.A., Cherwitz, R.A., CérdaPražák, A.A., and N. Bunch. 2012. What you get when you give: how graduate students benefit from serving as mentors. The Journal of Faculty Development 26:37-49.

Santora, K.A., Mason, E.J., and T.C. Sheahan. 2013. A model for progressive mentoring in science and engineering education and research. Innovative Higher Education 38:427-440. CrossRef

Seymour, E.L., Hunter, A-B., Laursen, S., and T. DeAntoni. 2004. Establishing the benefits of research experiences for undergraduates: first findings from a three-year study. Science Education 88:493-594. CrossRef 
Stoffer, B. 2015. Graduate student mentoring of undergraduates in the context of multi-level mentoring: individual, departmental, and university responsibilities. 2015. Ideas in Ecology and Evolution 8:2528. CrossRef

Thiry, H., Weston, T.J., Laursen, S.L., and A.B. Hunter. 2012. The benefits of multi-year research experiences: differences in novice and experienced students' reported gains from undergraduate research. CBE-Life Sciences Education 11: 260272. CrossRef

Young, A.M. and P.L. Perrewe. 2000. What did you expect? An examination of career-related support and social support among mentors and proteges. Journal of Management 26:611-632. 